\title{
GENESIS OF ORTHOPEDICS IN TAMIL NADU
}

In Tamil Nadu, the first orthopedic service was started in 1921 as outpatient services in the erstwhile Government General Hospital, Chennai, India. During those days, Orthopedics was like a specialty wing under General Surgery Department in the Government General Hospital, Chennai. Dr. N.S. Narasiman, General Surgeon in the Government General Hospital had a keen interest towards orthopedics during those days. To honor Dr. N.S. Narasiman, Tamil Nadu Orthopedic Association is organizing Dr. N.S. Narasiman oration during the annual state conference every year. In 1931, Dr. Mangalore Gopal Kini remembered as Dr. M.G. Kini was the first qualified orthopedic surgeon in Tamil Nadu, worked in the Government General Hospital, Chennai. Indian Orthopaedic Association is organizing Dr. M.G. Kini memorial oration every year in the Indian Orthopaedic annual conference to honor him. In 1949, separate orthopaedic department was established in the Government General Hospital by Lt. Col. V.R. Thayumanaswamy, first Professor of Orthopedic Surgery in Tamil Nadu. Later, Lt. Col. V.R. Thayumanaswamy became the Director of Medical Services for the entire state of Tamil Nadu.

\section{Genesis of Postgraduate Courses in Tamil Nadu Madras Medical College, Chennai}

In 1957, Prof. Mahalingam Natarajan took charge as Professor of Orthopedics and started postgraduate orthopaedic courses in Madras Medical College, the first in Tamil Nadu. Diploma in Orthopaedics was started in 1969 and Master of Surgery in Orthopaedics was started in 1973 in Madras Medical College, Chennai. Prof. T. K. Shanmugasundaram has pioneered the paraplegia management in the Government General Hospital and did extensive work on skeletal tuberculosis. To honor the great teachers, Prof. M. Natarajan Gold Medal for the best scientific paper in traumatology and Prof. T. K. Shanmugasundaram Gold Medal for the best scientific paper from rural part of Tamil Nadu are awarded by the Tamil Nadu Orthopedic Association in the annual state conference every year.

\section{Madurai Medical College, Madurai}

In Madurai, orthopedics branched out as a separate Department in Government Rajaji Hospital. Dr. Basheer Ahmed was the first qualified orthopedic surgeon in Government Rajaji Hospital, Madurai. Prof. S. T. Sundaraj was the first professor of orthopedics in Government Rajaji Hospital, Madurai. Prof. A. Subramaiam was responsible for the infrastructural development in Government Rajaji Hospital. In Madurai, Diploma Course in Orthopedics was started in 1969 and Master of Surgery in Orthopedic Course was started in 1973.

\section{Government Royapettah Hospital, Kilpauk Medical College, Chennai}

In Chennai, the Orthopedic Trauma Services was started in Government Royapettah Hospital under Kilpauk Medical College. Prof. Basheer Ahmed was the first professor of orthopedics in Government Royapettah Hospital and in 1981 Master of Surgery in orthopedics was started.

During those days, postgraduate Master degree orthopedic courses were available only in these three centers in Tamil Nadu.

\section{Coimbatore Medical College, Coimbatore}

In 1966, in Coimbatore Medical College, separate department of orthopaedics was established. Prof. Dhandayudham was the first professor of orthopaedics in Coimbatore Medical College. Prof. Ramadass was known for internal fixation of fractures on those days. In 2008, Master of Surgery postgraduate course in orthopaedics was started.

\section{Genesis of Tamil Nadu Orthopedic Association-A Platform to Share Knowledge}

In 1970, Tamilnadu Orthopaedic Association was formed by Robert Roaf and the annual conferences were organized with an objective of dissemination of orthopedic knowledge for the younger orthopedic surgeons and postgraduate students. Prof. M. Natarajan was the first president of the association and Prof. P.VA. Mohandas was the first secretary of the association. Prof. P.VA. Mohandas familiarized the concept of internal fixation for fractures in Tamil Nadu.

\section{Orthopaedic Association of South Indian States (OASIS)}

Prof. K. Annamalai and Prof. P.V. Vijayaraghvan were responsible for revival of Orthopaedic Association of South Indian States, a platform for knowledge sharing among South Indian states.

\section{Genesis of Subspecialties in Tamil Nadu}

In Chennai, Prof. K. Sriram started scoliosis corrective surgery and was instrumental for the development of pediatric orthopedic as a subspecialty in orthopedics. Prof. M. Subramaniam was known for his arthroplasty work in the Government side in Chennai. Similarly Prof. A. Devadas was known for arthroplasty advancement in Madurai. Dr. David V. Rajan was behind the development of Arthroscopy in Tamil Nadu. Prof. Mayilvahanan Natarajan was instrumental in the development of Orthopedic Oncology in Tamil Nadu.

Now orthopedics has branched out to many subspecialties like pediatric orthopedics, spine, foot and ankle, arthroplasty, arthroscopy, and musculoskeletal oncology, etc. in which post-doctorate fellowship courses are conducted by the Tamil Nadu Dr. M.G.R Medical University. 


\section{Department of Orthopedics Upgraded as Institute of Orthopedics and Traumatology}

Till now, two departments were upgraded as Institute of Orthopedics and Traumatology in Tamil Nadu.

In 2009, the department of orthopedics in Madras Medical College, was upgraded as Institute of Orthopedics and Traumatology by the untiring work of Prof. Mayilvahanan Natarajan.

In 2018, the department of orthopaedics, Coimbatore Medical College, was upgraded as Institute of Orthopedics and Traumatology by the active persistent involvement of Prof. S. Vetrivel Chezian.

\section{Diplomate of National Board Course in Orthopedics}

In between, the corporate hospitals in Tamil Nadu have started Diplomate of National Board course in orthopedics conducted by the National Board of Examination, New Delhi.

\section{Establishment of New Medical Colleges in Tamil Nadu}

With the development of Medical education in Tamil Nadu, Master of Surgery in Orthopedics course is present in most of the government and private medical colleges.

The infrastructure development is visible both on the government and private hospitals.

Ganga Hospital, Coimbatore, become one of the best centers of excellence in the world in orthopedics by the constant efforts of Dr. S. Rajasekaran.

In 1930, for orthopedic training, the medical professionals have to go abroad. In 2020, the scenario completely changed in Tamil Nadu. The latest advancements in orthopedics, all around the world, are very well available in Tamil Nadu.

Prof. S. Vetrivel Chezian, M.S (ortho), D. ortho, F.R.C.S, Ph.D 